Marc Buggeln, Michael Wildt (Hrsg.)

Arbeit im Nationalsozialismus 



\section{Arbeit im Nationalsozialismus}

Herausgegeben von

Marc Buggeln und

Michael Wildt 
Dieser Band geht zurück auf eine Tagung, die im Dezember 2012 im Internationalen Geisteswissenschaftlichen Kolleg „Arbeit und Lebenslauf in globalgeschichtlicher Perspektive“ (re:work) in Berlin stattfand, und konnte mit freundlicher Unterstützung des Kollegs gedruckt werden.

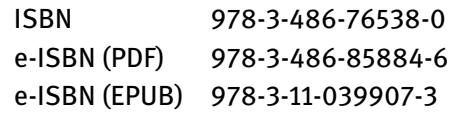

\section{Library of Congress Cataloging-in-Publication Data}

A CIP catalog record for this book has been applied for at the Library of Congress.

\section{Bibliografische Information der Deutschen Nationalbibliothek}

Die Deutsche Nationalbibliothek verzeichnet diese Publikation in der Deutschen Nationalbibliografie; detaillierte bibliografische Daten sind im Internet über http://dnb.dnb.de abrufbar.

(C) 2014 Oldenbourg Wissenschaftsverlag GmbH Rosenheimer Straße 143, 81671 München, Deutschland www.degruyter.com

Ein Unternehmen von De Gruyter

Titelbild: Hakenkreuzfahnen für den ,Tag der nationalen Arbeit' (1. Mai) werden in einer Fahnenfabrik vor der Färbung mit roter Farbe zum Trocknen aufgehängt. Photographie, Berlin 1933. @ akg images, Berlin.

Druck und Bindung: CPI books GmbH, Leck

Gedruckt in Deutschland

Dieses Papier ist alterungsbeständig nach DIN/ISO 9706

www.degruyter.com 